\title{
UPAYA MENINGKATKAN HASIL BELAJAR IPA MENGGUNAKAN \\ MODEL TWO STAY TWO STRAY DAN METODE PROBLEM SOLVING \\ PADA MIS HAYATUL ISLAMIYAH PALANGKA RAYA \\ TAHUN PELAJARAN 2018
}

\author{
Oleh : Noni Andayani*Karyanti, M.Pd
}

\begin{abstract}
Abstrak
Penelitian ini bertujuan untuk: (1) medeskripsikan aktivitas belajar peserta didik dalam pembelajaran IPA dengan menggunakan model pembelajaran Two Stay Two Stray dan metode Problem Solving, (2) Meningkatkan hasil belajar IPA peserta didik dengan menggunakan model pembelajaran Two Stay Two Stray Dan metode Problem Solving.

Bentuk penelitian yaitu penelitian tindakan kelas (PTK). Subjek penelitian adalah seluruh peserta didik kelas V MIs Hayatul Islamiyah Palangka Raya berjumlah 12 orang peserta didik yang terdiri dari 5 orang laki-laki dan 7 orang perempuan, analisis data menggunakan data kuntitatif dan kualitatif.

Hasil penelitian menunjukkan bahwa: (1) aktivitas belajar peserta didik menjadi sangat baik pada saat pembelajaran IPA dengan menggunakan model pembelajaran Two Stay Two Stray Dan metode Problem Solving. Siklus I, skor rata-rata aktivitas belajar peserta didik 3,73 dengan kriteria sangat baik, (2) ada peningkatan hasil belajar IPA dengan menggunakan model pembelajaran Two Stay Two Stray dan metode Problem Solving. Terlihat dari hasil belajar peserta didik pada tes awal memperoleh nilai rata-rata 58 (di bawah nilai $K K M \geq 65$ ) dengan ketuntasan klasikal 33,33\% dengan kriteria tidak tercapai. Siklus I memperoleh nilai rata-rata 88,75 dengan ketuntasan klasikal 100\% dengan kriteria tercapai.
\end{abstract}

Kata Kunci : Hasil Belajar IPA, Model Pembelajaran Two Stay Two Stray, Metode Problem Solving.

\section{PENDAHULUAN}

\section{Latar Belakang}

pendidikan nasional sebagai tercantum dalam Undang-Undang Nomor 20 Tahun 2003 tentang sitem pendidikan nasional pada pasal 1 butir (1) menjelaskan bahwa : Pendidikan adalah usaha sadar dalam tercantum untuk mewujudkan suasana belajar dan proses pembelajaran agar peserta didik secara aktif mengembangkan potensi dirinya untuk memiliki kekuatan spiritual keagamaan, pengendalian diri, kepribadian, kecerdasan, akhlak mulia, serta keterampilan yang diperlukan dirinya, masyarakat, bangsa dan negara. Dalam suatu pendidikan tidak lepas dari peranan tenaga kependidikan dan peserta didik itu sendiri. Peran guru dalam mencerdaskan kehidupan anak bangsa telah mendapat pengakuan seperti yang tercantum dalam Undang-Undang pada pasal 1 yang berbunyi : Guru adalah pendidik profesional dengan tugas utama mendidik, mengajar, membimbing, mengarahkan, melatih, menilai, dan mengevaluasi peserta didik pada pendidikan anak usia dini jalur pendidikan 
formal, pendidikan dasar dan pendidikan menengah. Pendidikan dasar atau sekolah dasar merupakan momentum awal bagi anak untuk meningkatkan kemampuan dirinya. Dari bangku sekolah dasarlah mereka mendapati imunitas belajar yang kemudian menjadi kebiasaan-kebiasaan yang mereka lakukan dikemudian hari. Dari sekolah dasarlah peserta didik mengenal pelajaran Ilmu Pengetahuan Alam, dimana dalam pembelajaran Ilmu Pengetahuan Alam terutama di sekolah dasar tidak lepas dari pengetahuan alam dan proses. Dalam rangka meningkatkan efektivitas proses pembelajaran terhadap materi pelajaran yang akan diajarkan maka sangat diperlukan keterampilan seorang guru dalam menyampaikan materi pelajaran. Untuk dapat mewujudkan proses pembelajaran yang efektif, maka guru harus menggunakan model dan motode pembelajaran yang tepat dalam proses pembelajaran agar memperoleh hasil belajar yang meningkat dan lebih baik lagi. Ilmu pengetahuan alam atau lebih baik dikenal dengan sebut IPA merupakan salah satu mata pelajaran yang sangat penting di sekolah dasar, IPA sendiri mempelajari segala sesuatu yang ada di alam. Baik itu makluk hidup maupun benda-benda mati, seperti hewan, tumbuhan, manusia, matahari, planet-planet, benda-benda angkasa, benda-benda yang membantu aktivitas manusia, tanah, air, udara, cuaca dan sebagainya.

Berdasarkan hasil observasi pada tgl 04 januari 2018 di MIs Hayatul Islamiyah pada kelas $\mathrm{V}$, peneliti menemukan permasalahan dari peserta didik yaitu kurangannya pemahaman peserta didik terhadap materi pembelajaran IPA pada materi peristiwa-peristiwa alam yang ada di indonesia dan dampak bagi lingkungannya. Peneliti mengamati dari 12 peserta didik ada sebagian besar peserta didik yang tidak memperhatikan guru pada saat proses pembelajaran berlangsung.

Dari fenomena yang ditemui, hal ini tidak terlepas dari peran guru pada saat proses pembelajaran berlangsung. Saat pembelajaran berlangsung guru diharapkan mampu membuat peserta didik aktif ikut serta dalam proses pembelajaran dan juga meningkatkan pemahaman peserta didik dengan materi yang diajarkan serta mampu meningkatkan hasil belajar. Tetapi dari hasil pengamatan, pada saat proses pembelajaran peneliti mengamati pembelajaran yang dilakukan kurang bervariasi, sehingga peserta didik kurang berpartisipasi dalam proses pembelajaran.

Pembelajaran dengan cara tersebut pada akhrinya membuat beberapa peserta didik merasa tidak bersemangat dan merasa bosan sehingga kurang aktif pada saat proses pembelajaran berlangsung. Sifat peserta didik seperti itu pada saat proses pembelajaran dapat mempengaruhi hasil belajar IPA khususnya materi peristiwa-peristiwa alam yang ada di indonesia dan dampak bagi lingkungannya. Hal ini membuktikan setelah dilakukannya pembelajaran materi peristiwa-peristiwa alam yang ada di indonesia dan dampak bagi lingkungannya, guru memberikan evaluasi dan terbukti dari proses pembelajaran tersebut ditemukan hasil belajar peserta didik kelas $\mathrm{V}$ dari 12 peserta didik ada 4 peserta didik (33\%) nilainya memenuhi KKM sedangkan 8 peserta didik (67\%) dibawah standar KKM yaitu 65. (Sumber Dari Guru)

Dari fenomena diatas dapat disimpulkan bahwa rendahnya hasil 
belajar IPA peserta didik disebabkan karena kurangnya variasi dalam proses pembelajaran yang dilaksanakan, sehingga peserta didik kurang partisipasi dalam proses pembelajaran karena itu proses dalam belajar dan memahami materi yang diberikan yang kemudian berpengaruh terhadap hasil belajar peserta didik. Untuk mengatasi hal tersebut salah satu model pembelajaran yang dapat digunakan yaitu dengan menerapkan model pembelajaran kooperatif two stay two stray dan metode problem solving.

\section{METODE PENELITIAN}

Penelitian ini adalah penelitian tindakan kelas atau yang lebih akarab di dengar yaitu PTK.

Menurut Elliot (Somadayo, 2013:19) bahwa : PTK adalah kajian tentang situasi sosial dengan maksud untuk meningkatkan kualitas kegiatan yang ada didalamnya, seluruh prpsesnya yang meliputi peneleaahan, pendiagnosaan, perencanaan, pelaksanaan, pemantauan, dan dampat yang diperlukan.

Menurut Kemmis dan Taggart (Somadayo, 2013:19) menyatakan bahwa: Penelitian tindakan adalah suatu bentuk penelitian reflektif diri yang secara kolektif dilakukan peneliti dalam situasi sosial untuk meningkatkan penalaran dan keadilan praktik pendidikan dan sosial mereka, serta pemahaman mereka praktik ini dan terhadap siswa tempat dilakukan praktik-praktik ini.

Dari pendapat beberapa ahli dapat disimpulkan bahwa penelitian tindakan yang dilakukan oleh guru terhadap kegiatan dalam proses pembelajaran dikelas dengan suatu model two stay two stray dan metode problem solving, melibatkan partisipasi dan tindakan yang dilakukan secara bersama melihat kondisi kelas untuk mencapai suatu tujuan serta pendidikan yang lebih baik. Penelitian tindakan kelas adalah penelitian reflatif yang dilakukan oleh guru untuk mengembangkan keahlian mengajar dan hasilnya dimanfaatkan untuk meningkatkan aktivitas dan hasil belajae peserta didik.

Berdasarkan jenis penelitian yang digunakan yaitu penelitian tindakan kelas (PTK), maka peneliti hadir selama penelitian disekolah berlangsung. Peran peneliti adalah melakukan penelitian dan berklaborasi dengan guru kelas $\mathrm{V}$ dan dibantu oleh teman sejawat sebagai observer agar penelitian dapat berjalan dengan lancar dan mencapai tujuan pembelajaran yang diharapkan. Di samping itu, peneliti juga mengumpulkan dan menganalisis data serta sebagai pelapor hasil penelitian.

Dalam pelaksanaan penelitian tindakan kelas ini yang menjadi subjek penelitian adalah peserta didik kelas $\mathrm{V}$ semester genap yang berjumlah 12 orang. Terdiri dari 7 peserta didik perempuan dan 5 peserta didik laki-laki. Sedangkan yang menjadi objek penelitian adalah hasil belajar IPA.

Data yang telah dikumpulkan dari dari setiap kegiatan yang dilaksanakan dalam siklus PTK nantinya akan dianalisis secara deskriptif. Data yang diperoleh melalui instrumen yang telah dikumpulkan sebelumnya diolah menjadi dua jenis data yaitu kuantitatif dan kualitatif.

Pengumpulan data yang diperoleh pada penelitian ini dilakukan melalui pengamatan (observasi) dan tes hasil belajar. 
Menurut Creswell dan Plano dalam Wina Sanjaya (2012: 49) menjelaskan mixed methods atau metode campuran adalah "pedoman pada arah dari kumpulan analisis data dan gabungan dari penelitian kualitatif dan kuantitatif dalam banyak fase pada proses penelitian"..

\section{HASIL DAN PEMBAHASAN}

Data dari hasil penelitian ini berupa : 1) pengamatan aktivitas guru dan peserta didik
Data kuantitatif berasal dari hasil tes yang diberikan pada setiap akhir siklus kegiatan. Hal ini dilakukan untuk mengetahui peningkatan hasil belajar peserta didik pada pendekatan yang diterapkan.

2) hasil belajar IPA menggunakan model pembelajaran Think Pair Share berbantukan media visual.

3) Pengamatan aktivitas guru dan peserta didik

Aktivitas guru dan peserta didik dapat dilihat pada tabel dan gambar berikut :

\section{Tabel 1}

\section{Rekapitulasi Data Pengamatan}

Aktivitas Guru dan Peserta didik

\begin{tabular}{|l|l|l|}
\hline \multirow{2}{*}{ No. } & \multicolumn{2}{|l|}{ Aktifitas } \\
\cline { 2 - 3 } & Guru & Peserta Didik \\
\hline \multirow{2}{*}{. } & 3,83 & 3,73 \\
\hline
\end{tabular}

Sumber data : Pengamatan Tahun 2017 (Dua orang observer)

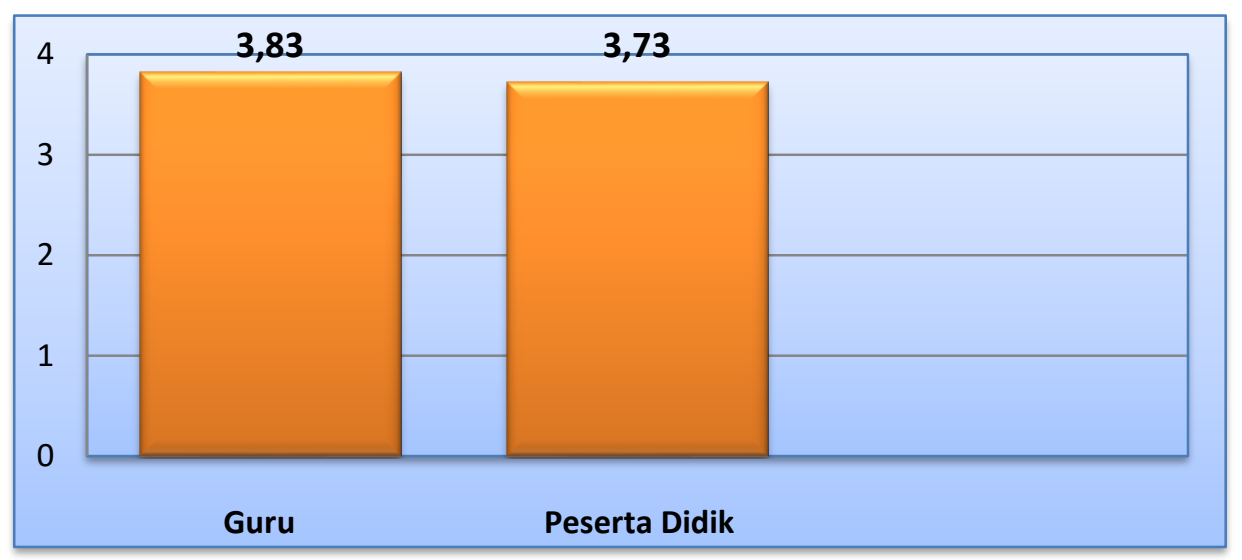

Berdasarkan tabel di atas, melalui pembelajaran menggunakan model pembelajaran Two stay two stray dan metode problem solving oleh peneliti di kelas V di MIs Hayatul Islamiyah Palngkaraya aktivitas guru dan peserta didik menunjukan suatu peningkatan yang baik dari observasi 
Tabel 2

Data Hasil Belajar Post Test Siklus I Kelas V MIs Hayatul Islamiyah

\begin{tabular}{|c|c|c|c|c|}
\hline \multirow[b]{2}{*}{ No. } & \multirow{2}{*}{$\begin{array}{ll}\text { Kode } & \text { Peserta } \\
\text { Didik } & \end{array}$} & \multirow[b]{2}{*}{ Nilai Siklus I } & \multicolumn{2}{|c|}{ Ketuntasan } \\
\hline & & & $\begin{array}{l}\text { Tuntas } \\
T \geq 65\end{array}$ & $\begin{array}{l}\text { Tidak Tuntas } \\
\text { TT }<65\end{array}$ \\
\hline 1. & $\mathrm{CL}$ & 90 & Tuntas & \\
\hline 2. & IR & 100 & Tuntas & \\
\hline 3. & MD & 95 & Tuntas & \\
\hline 4. & MJ & 100 & Tuntas & \\
\hline 5. & $\mathrm{MH}$ & 85 & Tuntas & \\
\hline 6. & NI & 95 & Tuntas & \\
\hline 7. & RA & 70 & Tuntas & \\
\hline 8. & SR & 100 & Tuntas & \\
\hline 9. & TSR & 80 & Tuntas & \\
\hline 10. & JS & 95 & Tuntas & \\
\hline 11. & RA & 70 & Tuntas & \\
\hline 12. & RJ & 85 & Tuntas & \\
\hline \multicolumn{2}{|c|}{ Jumlah } & 1065 & \multirow{3}{*}{\multicolumn{2}{|c|}{ Tercapai }} \\
\hline \multicolumn{2}{|c|}{ Rata-rata } & 88,75 & & \\
\hline \multicolumn{2}{|c|}{ Ketuntasan } & 100 & & \\
\hline
\end{tabular}

Sumber Data : Penelitian Tahun 2018

Berdasarkan tabel hasil post test pada siklus I terlihat hasil belajar peserta didik kelas V MIs Hayatul Islamiyah Palangkaraya dengan rata-rata 88,75 dengan ketuntasan klasikal mencapai $100 \%$ ini berarti pada siklus ke I ketuntasan belajar individu sudah mencapai dan dianggap tuntas, jadi tidak perlu ada tindakan selanjutnya untuk memperbaiki hasil belajar kelas V MIs
Hayatul Islamiyah Palangkaraya karena target dalam penelitian ini adalah standar KKM 65 sudah tercapai, dan tingkat ketercapaian ketuntasan hasil belajar peserta didik secara klasikalnya sudah melebihi target yang diinginkan, yaitu $85 \%$.

Adapun peningkatan hasil belajar dapat dilihat dalam gambar diagram berikut 


\section{Gambar 5}

Diagram Hasil Rekapitulasi Nilai Rata-Rata dan Ketuntasan

Hasil Belajar Matematika Peserta Didik Kelas III SDN 3 Palangka

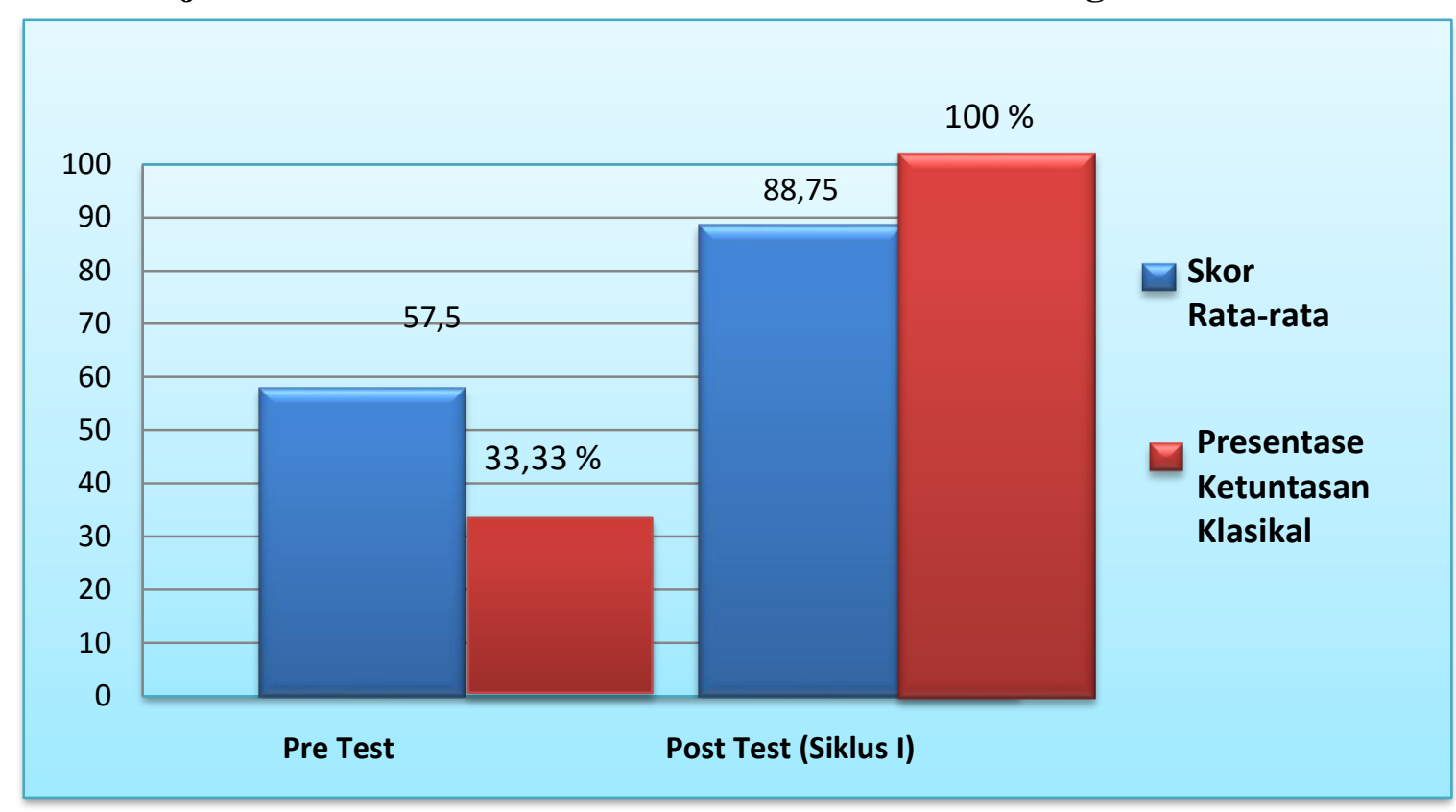

\section{SIMPULAN}

Berdasarkan data dari hasil penelitian dan pembahasan dalam penelitian tindakan kelas (PTK) pada siklus I di kelas V MIs Hayatul Islamiyah, maka dapat diambil kesimpulan sebagai berikut:

1. Aktivitas peserta didik kelas V MIs Hayatul Islamiyah tahun pelajaran 2017/2018 dalam pembelajaran IPA dengan menggunakan model pembelajaran Two Stay Two Stray dan metode Problem Solving menjadi sangat baik, karena peserta didik aktif, antusias, mendengarkan penjelasan guru serta bersemangat dalam mengikuti proses pembelajaran. Adapun hasil pengamatan akivitas guru pada kegiatan belajar mengajar yang dilakukan oleh pengamat I dan pengamat II selama proses pembelajaran IPA pada siklus I ratarata aspek aktivitas guru 3,83 pada kategori sangat baik, dan rata-rata aspek peserta didik yaitu 3,73 pada kategori sangat baik.

2. Hasil penelitian ada peningkatan: (1) aktivitas belajar peserta didik menjadi sangat baik pada saat pembelajaran IPA dengan menggunakan model pembelajaran Two Stay Two Stray Dan metode Problem Solving. Siklus I, skor rata-rata aktivitas belajar peserta didik 3,73 dengan kriteria sangat baik, (2) ada peningkatan hasil belajar IPA dengan menggunakan model pembelajaran Two Stay Two Stray dan metode Problem Solving. Terlihat dari hasil belajar peserta didik pada tes awal memperoleh nilai rata-rata 58 (di bawah nilai KKM $\geq 65$ ) dengan ketuntasan klasikal $33,33 \%$ dengan kriteria tidak tercapai. Siklus I memperoleh nilai rata-rata 88,75 dengan ketuntasan klasikal 100\% dengan kriteria tercapai.

\section{DAFTAR PUSTAKA}

Somadayo, Samsu. (2013). Penelitian Tindakan Kelas. Yogyakarta : Graha Ilmu 
Pedagogik Jurnal Pendidikan, Maret 2018, Volume 13 Nomor 1, (48-54) 